\title{
Effects of Electrical Stimulation in People with Post-Concussion Syndromes: A Pilot Study
}

\author{
Yi-Ning Wu1, Jessica Gravel ${ }^{2,3}$, Naseem Chatiwala ${ }^{2,3}$, Terrie Enis ${ }^{1,2,3}$, Caroline Stark ${ }^{1}$, \\ Robert C. Cantu ${ }^{2,4^{*}}$
}

\author{
${ }^{1}$ Department of Physical Therapy, University of Massachusetts Lowell, Lowell, MA, USA \\ ${ }^{2}$ Dr. Robert C. Cantu Concussion Center, Emerson Hospital, Concord, MA, USA \\ ${ }^{3}$ Center for Rehabilitative and Sports Therapies, Emerson Hospital, Concord, MA, USA \\ ${ }^{4}$ Department of Neurosurgery and Neurology, Boston University School of Medicine, Boston, MA, USA \\ Email: ${ }^{*}$ cantu@emersonhosp.org
}

How to cite this paper: Wu, Y.-N., Gravel, J., Chatiwala, N., Enis, T., Stark, C. and Cantu, R.C. (2018) Effects of Electrical Stimulation in People with Post-Concussion Syndromes: A Pilot Study. Health, 10, 381-395. https://doi.org/10.4236/health.2018.104031

Received: February 17, 2018

Accepted: April 13, 2018

Published: April 16, 2018

Copyright (c) 2018 by authors and Scientific Research Publishing Inc. This work is licensed under the Creative Commons Attribution International License (CC BY 4.0).

http://creativecommons.org/licenses/by/4.0/

\section{cc) (i) Open Access}

\begin{abstract}
Post-concussion syndrome (PCS) is a complex disorder with various symptoms. There is limited evidence to support that any intervention enhances recovery after a concussion. This pilot study aimed to examine the efficacy of neck paraspinal muscles electrical stimulation (ES) in conjunction with physical therapy (PT) on reducing the severity of post concussive symptoms. Twenty-four individuals with PCS were randomly assigned to the ES group $(\mathrm{PT}+\mathrm{ES})$ or the control group (PT only). Both groups received the intervention twice a week for eight weeks. Clinical measures including the Concussion Signs/Symptoms Checklist, balance error scoring system, King-Devick test, ImPACT, and the Standardized Assessment of Concussion were used to evaluate the symptoms. We investigated the recovery rate by calculating slopes of changes over time for each participant. A changing slope was derived by linearly fitting the symptoms severity over time with the initial severity score as the intercept. Significant overall improvement was observed in both groups after the interventions. There was no significant difference seen in total symptom recovery rate between two groups $(-1.49 \pm 1.59$ versus $-1.2 \pm 1.56$, $\mathrm{p}=0.32)$. The cognitive symptoms recovery rate of the ES group was faster than the control group $(-0.5 \pm 0.49$ and $-0.13 \pm 0.46$ respectively, $\mathrm{p}=0.04)$. Physical therapy targeting the cervical region is beneficial for persons with PCS. Moreover, peripheral electrical stimulation on the paraspinal muscles surrounding the neck region could potentially advance the cognitive function recovery of persons with PCS.
\end{abstract}

\section{Keywords}

Post-Concussion Syndrome, Cognitive Function, Physical Therapy, Electrical 
Stimulation

\section{Introduction}

Concussion, a form of mild traumatic brain injury, affects more than 600 per 100,000 individuals each year [1]. About 1.6 to 3.8 million concussions occur in sports and recreational activities annually as estimated by the Centers for Disease Control [2]. The majority of symptoms resolve in 7 - 10 days [3] (or within one month for most children and adolescents [4]). If the concussion is not sport-related, most individuals recover completely within the first three months [5] [6]. However, approximately $10 \%$ of athletes have persistent concussion symptoms beyond two weeks and up to $33 \%$ of non-athletes may have symptoms beyond three months [7]. The prolonged symptoms may indicate post-concussion syndrome (PCS). Post-concussion syndrome (PCS) is a complex disorder in which concussion symptoms last for weeks, months and, in rare cases, years. The essentials of concussion management fall into four categories, education, baseline testing, injury assessment and injury management. Currently, the majority of articles in the literature focus on the diagnosis of mild traumatic brain injury; the evidence for treating persistent symptoms after concussion remains scarce [8].

Many current recommendations are based on anecdotal evidence, consensus or limited literature. With respect to concussion treatment, a period of cognitive and physical rest in the early stage post-injury is recommended [9] [10]. When asymptomatic at rest, concussed individuals should progress to light physical activity [11]. Some literature and clinicians' experience show promising avenues for treating PCS [12], but further studies are still required as the American Academy of Neurology stated that "data are insufficient to show that any intervention enhances recovery or diminishes long-term sequelae post concussion" [13]. Because of the diverse symptoms associated with PCS, a coordinated multidisciplinary team service is preferable to treat not only the brain but also other structures involved [14] in the PCS. Potential damages to various structures could occur following a concussive injury. Those structures include the peripheral and central vestibular systems, as well as the cervical spine. Those differences might require different treatments. Limited diagnostic tools and insufficient evidence of treating PCS make it difficult for clinicians to choose an effective approach. Consequently, there is significant variability in concussion care practices [15]. Research utilizing a pathophysiological approach [16] that takes the potential source of injury and predominant symptoms into account when treating PCS might provide consistent evidence for PCS care.

The importance of active rehabilitation for PCS has emerged [17]. It is suggested that if a cervical source is suspected to contribute to ongoing symptoms, physical therapy will play an important role and should be instituted to treat 
abnormal neck functions [17]. Ellis et al. demonstrated evidence that individuals with cervicogenic PCS suffer limited neck range of motion, neck pain, headache, etc. [18]. Furthermore, in addition to the cervical dysfunctions, cognitive functions are often reported to affect daily performance at school or at work by individuals with PCS. Improving cervical functions as well as cognitive functions can enhance the quality of life of individuals with PCS, especially those with cervical spine involvement. Physical therapy, particularly manual therapy, has been shown to be effective in alleviating neck pain, headache, and dizziness in individuals with disorders other than PCS [19] [20]. On the same note, electrical stimulation (ES) is widely used in physical therapy to manage pain either directly or indirectly [21] [22] [23] [24]. ES also demonstrated positive effects on non-pain related cognitive functioning [25] [26] [27]. For example, transcutaneous electrical stimulation delivering electrical currents peripherally was found to have central effects that further improve cognition and mood in persons with Alzheimer's disease and in ageing populations [26]. It was suggested that electrical stimulation could activate brain structures indirectly mediated by the ascending reticular activating system or through spinoseptal and spinohypothalamic pathways to the hippocampus and hypothalamus [26] or the vestibular pathways [28] to enhance cognitive functions. Owing to the effects of physical therapy and ES in treating the symptoms observed in other disorders, a PT regimen including ES may shed a light not only on alleviating the overall post concussive symptoms but also enhancing the cognitive functions in individuals with cervicogenic PCS. Therefore, the objective of this study was to examine the efficacy of ES on the neck paraspinal muscles in conjunction with PT on reducing the PCS symptoms compared to PT alone in individuals with cervicogenic PCS. We hypothesized that both groups would demonstrate positive outcomes but the cognitive functions of the ES group would recover in a faster manner.

\section{Methods}

\subsection{Participants}

A double-blind-cohorts study design was used in this study. Participants were blinded as to which group they comprised. The evaluator who was responsible for scoring clinical measures before and after the intervention remained blind throughout the study. Only the physical therapists trained to provide the experimental protocol were aware of which participants were receiving the experimental treatment or placebo. A convenience sample of 24 participants with PCS was recruited from the Emerson Hospital and randomly assigned to the ES group (PT + ES) or the control group (PT only). This was done by randomly picking the first assigned participant by a coin toss and the subsequent participants were assigned based on alternating one to the ES group and the next to the control group. Inclusion criteria included 1) with PCS diagnosis, 2) at minimum age of 13 years old, and 3) be able to follow instructions. All participants exhi-

bited cervical spine involvement such as trigger points, limited neck range of 
motion and neck pain. Participants who were diagnosed with other neurological disorders or were receiving other treatments such as occupational therapies, speech therapies, cognitive therapies and research pharmacotherapy for concussion were excluded. In addition, participants with ES contraindications [29] including potential pregnancy, the presence of cardiac pacemaker or other implanted electrical stimulator, the presence of cancer and broken skin around the neck and upper back were excluded. Table 1 shows the composition of groups

Table 1. Characteristics of participants at the time of recruitment.

\begin{tabular}{|c|c|c|c|c|c|c|}
\hline \multicolumn{7}{|c|}{ ES group } \\
\hline Participant No. & Age (years) & Gender & SAC & Athlete or not & CheckList severity & $\begin{array}{l}\text { Days since the last concussion } \\
\text { Months (m), weeks (w), days (d) }\end{array}$ \\
\hline E01 & 16 & M & 25 & Yes & 12 & $9-10 m$ \\
\hline E02 & 22 & M & 28 & No & 15 & $3 \mathrm{~m}$ \\
\hline E03 & 16 & $\mathrm{~F}$ & 26 & No & 30 & $34 \mathrm{~m}$ \\
\hline E04 & 22 & $\mathrm{~F}$ & 10 & No & 13 & $2 \mathrm{w}$ \\
\hline E05 & 49 & $\mathrm{~F}$ & 29 & No & 36 & $7 \mathrm{~m} 2 \mathrm{w}$ \\
\hline E06 & 19 & $\mathrm{~F}$ & 22 & Yes & 44 & $6 \mathrm{~m}$ \\
\hline E07 & 16 & F & 29 & Yes & 37 & $1 \mathrm{~m}$ \\
\hline E08 & 19 & F & 28 & Yes & 13 & $7 \mathrm{~m}$ \\
\hline E09 & 54 & $\mathrm{~F}$ & 26 & No & 15 & $6 \mathrm{~m}$ \\
\hline E10 & 59 & $\mathrm{~F}$ & 27 & No & 24 & $2 \mathrm{~m}$ \\
\hline E11 & 54 & $\mathrm{~F}$ & 14 & No & 79 & $6 \mathrm{w}$ \\
\hline E12 & 43 & M & 28 & No & 42 & $9 \mathrm{~m}$ \\
\hline Mean \pm SD & $32.42 \pm 17.61$ & $3 \mathrm{M}, 9 \mathrm{~F}$ & $24.33 \pm 6.14$ & 4 athletes & $30 \pm 19.57$ & 2 weeks - 10 months \\
\hline \multicolumn{7}{|c|}{ Control group } \\
\hline Participant No. & Age (years) & Gender & SAC & Athlete or not & Checklist severity & $\begin{array}{l}\text { Days since the last concussion } \\
\text { Months (m), weeks (w), days (d) }\end{array}$ \\
\hline $\mathrm{C} 01$ & 13 & M & 27 & Yes & 18 & $19 \mathrm{~d}$ \\
\hline $\mathrm{C} 02$ & 19 & M & 27 & No & 34 & $2 \mathrm{~m}$ \\
\hline $\mathrm{C} 03$ & 38 & M & 27 & No & 4 & $7 \mathrm{~m}$ \\
\hline $\mathrm{C} 04$ & 20 & M & 28 & Yes & 29 & $5 \mathrm{~m}$ \\
\hline $\mathrm{C} 05$ & 25 & $\mathrm{~F}$ & 27 & Yes & 21 & $7 \mathrm{~m}$ \\
\hline $\mathrm{C} 06$ & 20 & M & 28 & Yes & 16 & $11 \mathrm{~m}$ \\
\hline $\mathrm{C} 07$ & 16 & $\mathrm{~F}$ & 28 & No & 33 & $4 \mathrm{~m}$ \\
\hline $\mathrm{C} 08$ & 42 & $\mathrm{~F}$ & 28 & No & 23 & $3 \mathrm{~m}$ \\
\hline $\mathrm{C} 09$ & 45 & $\mathrm{~F}$ & 26 & No & 28 & $6 \mathrm{~m}$ \\
\hline $\mathrm{C} 10$ & 51 & $\mathrm{~F}$ & 24 & No & 42 & $2-3 w$ \\
\hline $\mathrm{C} 11$ & 50 & $\mathrm{~F}$ & 23 & No & 44 & $19 \mathrm{~m}$ \\
\hline $\mathrm{C} 12$ & 19 & M & 27 & Yes & 26 & $10 \mathrm{~m}$ \\
\hline Mean \pm SD & $29.83 \pm 14.22$ & $6 \mathrm{M}, 6 \mathrm{~F}$ & $26.67 \pm 1.61$ & 5 athletes & $26.5 \pm 11.22$ & 2 weeks - 19 months \\
\hline
\end{tabular}

SAC: standardized assessment of cognition, SD: standard deviation. 
and the characteristics of each participant at the time of recruitment. Written informed consent and assent if appropriate were obtained from all participants before any experimental procedures took place. The protocol was approved by Emerson Hospital's Institutional Review Board.

\subsection{Interventions}

Participants received the eight-week, 16 sessions, of assigned intervention (conventional PT with ES or conventional PT only) at the frequency of twice a week for eight weeks. Both groups received conventional PT based on each individual's signs, risk factors, and goals. The conventional PT including soft tissue mobilization [30], cervical muscles stretching and strengthening were administered by physical therapists. The study regimen, electrical stimulation, was administered to the ES group followed by the conventional PT. We used MyoWorx" TM20 (MyoWorx Inc., Guelph, ON, Figure 1) to deliver electrical stimulation to the participant in a private room with dimmed lights while the participant remained in a supportive supine posture (Figure 1). The machine delivered a sequence of frequencies in a timed manner to the paraspinal muscles. Figure 1 illustrates the electrodes placement. The ES was on for 30 minutes. The amplitude of stimulation was adjusted based on the patient's comfort level without any evidence of visible or tactile muscle twitching. The control group had the electrodes on but the machine did not deliver any electrical current to the body. To reduce placebo effect, we instructed participants in the control group that the stimulation was sub-maximal threshold and that they should not perceive any sensation.

\subsection{Outcome Measures}

Primary outcome measures. The primary outcome measure was the Dr. Cantu Concussion Signs/Symptoms Checklist [31] [32], a published scale that is recommended to assist clinicians in tracking the number and severity of concussion-related symptoms. Dr. Cantu concussion Signs/Symptoms Checklist, Checklist hereafter, is a 7-point $(0$ - 6) Likert-style self-report questionnaire rating 26 concussion-related symptoms in somatic, cognitive, affective and sleep
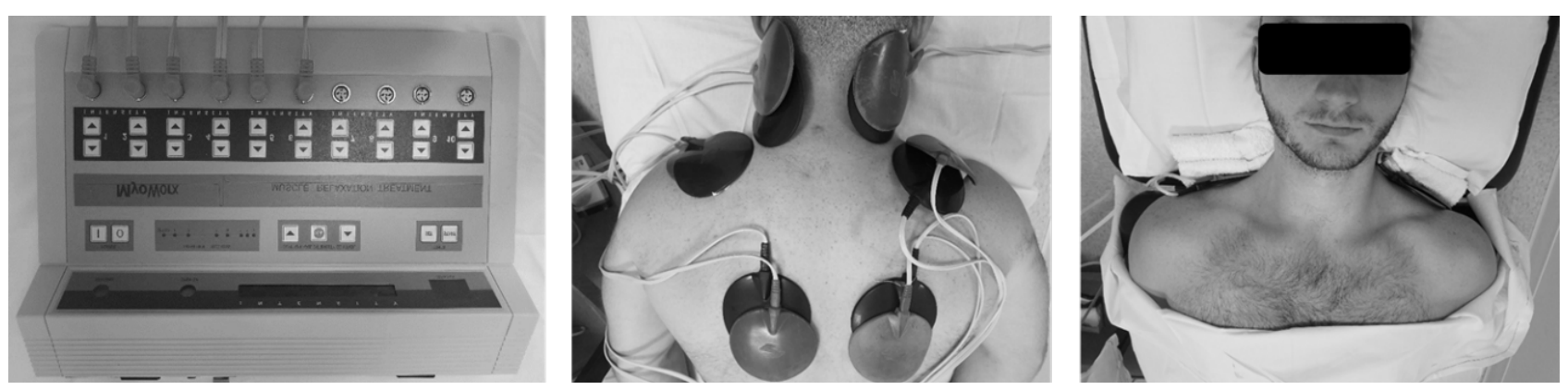

Figure 1. Left: The machine used in the study to deliver electrical stimulation. Middle and right: The electrodes were placed on the thoracic paraspinal muscles, another at bilateral upper traps, and the last at the cervical paraspinal muscles. After placing the electrodes, the participant lay supine in the dimmed room. The same setup was used for both groups but only the ES group had the power of machine on. 
domains. Beyond the total symptoms severity score of the Checklist, we examined the changes of symptoms severity by domains as previous research suggested [33]. The cognitive domain contains seven symptoms, which are "confusion", "difficulty concentrating", "difficulty remembering”, "don't feel right/dinged/bell rung", "drowsy", "feeling in a fog" and "loss of consciousness". The affective domain includes "feeling more emotional", "irritability", "nervous/anxious", and "sadness". The 12 signs in the somatic domain are "balance", "dizziness", "fatigue/low energy", "feeling slow down", "headache/head pressure", "nausea/vomiting", "neck pain", "numbness/tingling", "ringing in the ears", "sensitivity to light", "sensitivity to noise", and "visual problems/blurred vision". The sleep domain contains "sleeping less than usual", "sleeping more than usual" and "trouble falling asleep". In addition to the aforementioned four domains, we segregated items related to the vestibulo-ocular dysfunctions including "balance", "dizziness", "nausea/vomiting", "neck pain" and "visual problems/blurred vision". The Checklist was filled out by the participants before and after the eight-week intervention as well as before each treatment session started. We investigated the progress of recovery by calculating the slope of changes of Check List symptoms severity over the eight-week intervention in each participant. A changing slope was derived by linearly fitting the symptoms severity over 18 treatment sessions with the initial severity score as the intercept. A more negative slope represented a faster recovery.

Secondary outcome measures used before and after the interventions. It is recommended that evaluation of cognition, oculomotor function, gross sensorimotor, coordination, vestibular function and balance should be included in assessment for concussion management [34]. Therefore, to assess the post-concussion injury, testing of multiple domains rather than relying on one area of measurement would be preferred [35] [36]. The improvement in one domain might influence the performance of the other domains. Therefore, before and after the eight-week intervention, we also assessed the participants using the following commonly used instruments; Balance Error Scoring System (BESS) was used to assess postural stability [3], the King-Devick Test was used to assess visual tracking and saccadic eye movements [37] and the Immediate Post-Concussion Assessment and Cognitive Testing (ImPACT) and the Standardized Assessment of Concussion (SAC) [38] were used to assess the related functions of participants.

\subsection{Statistical Analysis}

The mixed-design ANOVA was used to compare outcome measures before and after the intervention between and within the two groups. The between group factor had two levels: the ES and the control groups. The within factor corresponded to the repeated measures over time and had two levels of pre-intervention and post-intervention. Independent t-test was used to assess the differences of the cognitive function recovery rate (the slopes of cognitive 
symptoms severity changes over eight-week intervention) between two groups. All statistical analyses were performed using SPSS with the significance level of $\mathrm{p}<0.05$.

\section{Results}

All participants completed the interventions. However, due to schedule conflicts, two participants of the ES group did not complete the ImPACT test and one among these two did not complete SAC. BESS was not performed on one participant in the control group due to a leg injury before the intervention. No adverse events were reported when the electrical stimulation was applied to participants.

\subsection{Symptoms Severity Changes and Cognitive Function Recovery Rate}

Table 2 shows the mixed-design ANOVA results of the Checklist between groups before and after the interventions. The improvement seen in the total symptoms severity of both groups after the interventions did not differ significantly. Both groups had significant improvement after the intervention ( $\mathrm{p}<$ 0.001). The same results were found when we examined each domain independently. The results were consistent with the findings of secondary outcome measures.

When we looked at the recovery rate, no significant difference was found in the recovery rates of total symptoms severity between two groups $(-1.49 \pm 1.59$ versus $-1.2 \pm 1.56, \mathrm{p}=0.32$ ). The cognitive symptoms severity of both groups decreased toward the end of the eight-week interventions and the ES group had a quicker recovery compared to the control group. Figure 2 shows that the

Table 2. Comparisons of CheckList score changes between groups per each domain and all domains combined.

\begin{tabular}{|c|c|c|c|c|c|c|}
\hline & & $\begin{array}{l}\text { Pre-Intervention } \\
\text { Mean (SD) }\end{array}$ & $\begin{array}{l}\text { Post-Intervention } \\
\quad \text { Mean (SD) }\end{array}$ & $\begin{array}{l}\mathrm{p} \text { Value } \\
\text { (Time) }\end{array}$ & $\begin{array}{l}\text { p Value } \\
\text { (Group) }\end{array}$ & $\begin{array}{l}\mathrm{p} \text { Value } \\
\text { (Time } \times \\
\text { Group) }\end{array}$ \\
\hline \multirow[t]{2}{*}{ Total (/156) } & ES & $30(19.57)$ & $10.33(9.8)$ & $<0.001$ & 0.703 & 0.564 \\
\hline & Control & $26.5(11.22)$ & $10.42(9.35)$ & & & \\
\hline \multirow[t]{2}{*}{ Cognitive (/42) } & ES & $8.45(6.76)$ & $2.27(2.94)$ & $<0.001$ & 0.641 & 0.583 \\
\hline & Control & $7.17(4.34)$ & $2.08(2.54)$ & & & \\
\hline \multirow[t]{2}{*}{ Affective (/24) } & ES & $2.91(3.78)$ & $0.55(1.21)$ & 0.002 & 0.353 & 0.392 \\
\hline & Control & $1.75(1.82)$ & $0.33(0.49)$ & & & \\
\hline \multirow[t]{2}{*}{ Somatic (/72) } & ES & $13.91(9.2)$ & $7(7.22)$ & $<0.001$ & 0.986 & 0.82 \\
\hline & Control & $14.33(7.55)$ & $6.67(5.52)$ & & & \\
\hline \multirow[t]{2}{*}{ Sleep (/18) } & ES & $3.45(3.67)$ & $1(1.48)$ & 0.009 & 0.662 & 0.633 \\
\hline & Control & $3.5(3.09)$ & $1.75(2.34)$ & & & \\
\hline \multirow[t]{2}{*}{$\operatorname{VO}(/ 30)$} & ES & $5(4.27)$ & $2.73(2.69)$ & 0.001 & 0.173 & 0.7 \\
\hline & Control & $3.75(2.83)$ & $1(1.21)$ & & & \\
\hline
\end{tabular}

VO: vestibulo-ocular domain. 


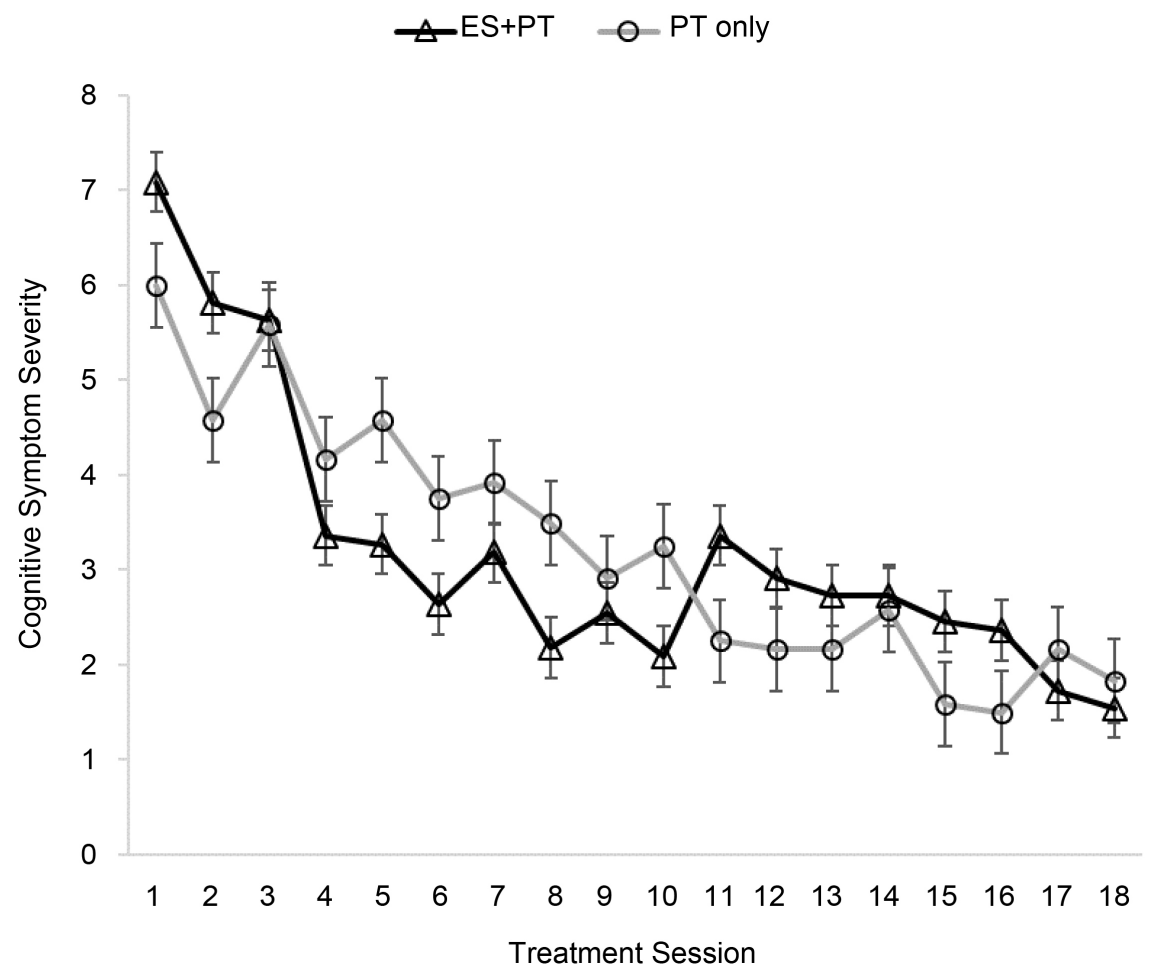

Figure 2. Grouped data with standard error bars of cognitive functions recovery tracked by the cognitive domain of Checklist. The open circle gray line represents data of the control group and the open triangle line represents the data of the ES group. There was a significant difference between cognitive function recovery rates of the two groups.

averaged slope of the ES group was significantly more negative than the slope of the control group $(-0.5 \pm 0.49$ and $-0.13 \pm 0.46$ respectively, $p=0.04)$.

\subsection{Secondary Outcome Measures}

Table 3 presents the changes of secondary outcome measures in both groups. The mixed-design ANOVA showed that there was no interaction between time and group in all the secondary measures. The change patterns of all secondary outcome measures in the two groups were not significantly different. Significant main effect for time was observed in BESS, King-Devick test, verbal memory composite of ImPACT and SAC $(\mathrm{p}<0.001, \mathrm{p}=0.001, \mathrm{p}=0.009$ and $\mathrm{p}=0.014$ respectively). The visual memory composite of ImPACT exhibited the trend of increasing scores after the interventions in both groups $(\mathrm{p}=0.08)$.

\section{Discussion}

To our knowledge, this is the first study examining the effects of peripheral electrical stimulation on individuals with post-concussion syndrome. Our study results contribute to the current body of evidence on cervical rehabilitation for PCS as well as the involvement of cervical spine in post-concussion syndromes. The electrical stimulation via MyoWorx" TM20 as an adjunct to treatment for persons with PCS was safe since we did not observe any adverse events occurring 
Table 3. Means and $95 \%$ confidence intervals of outcome measures in both groups.

\begin{tabular}{|c|c|c|c|c|}
\hline \multirow{2}{*}{$\begin{array}{c}\text { Groups } \\
\text { Evaluation Time }\end{array}$} & \multicolumn{2}{|c|}{ ES Group } & \multicolumn{2}{|c|}{ Control Group } \\
\hline & pre & post & pre & post \\
\hline BESS & $18.58[14.77-22.4]$ & $10.25[6.99-13.51]$ & $15.55[11.56-19.53]$ & $9.36[5.96-12.77]$ \\
\hline King-Devick & $66.65[49.62-83.68]$ & $44.74[39.13-50.34]$ & $53.42[36.39-70.45]$ & $39.36[33.76-44.97]$ \\
\hline SAC & $24.55[21.68-27.41]$ & $27.82[26.88-28.75]$ & $26.67[23.93-29.41]$ & $28.5[27.61-29.4]$ \\
\hline ImPACT-visual memory & $65.3[52.67-77.93]$ & $73.3[61.87-84.73]$ & $76.67[65.14-88.2]$ & $80.17[69.73-90.6]$ \\
\hline ImPACT-impulse control & $6.1[1.63-10.57]$ & $8.1[3.04-13.16]$ & $5.33[1.25-9.42]$ & $4.58[0-9.2]$ \\
\hline ImPACT-motor speed & $34.87[28.62-41.12]$ & $36.54[31.78-41.32]$ & $38.31[32.6-44.02]$ & $40.1[35.74-44.45]$ \\
\hline ImPACT-reaction time (sec) & $0.65[0.547-0.77]$ & $0.64[0.58-0.7]$ & $0.69[0.58-0.79]$ & $0.59[0.54-0.65]$ \\
\hline
\end{tabular}

to the participants recruited in the study.

\subsection{ES May Expedite the Cognitive Function Recovery}

While both groups showed overall improvement, the ES group demonstrated a relatively faster recovery in the cognitive domain compared to the control group. Individuals with PCS suffering with upper cervical spinal injury may have compromised vestibulo-thalamo-cortical pathways or other pathways anatomically located posteriorly in the body near where we applied ES that are potentially involved in cognitive functions [28]. The electrical stimulation enhancing the cognitive function recovery might be in part due to the ES modulating the neural activity or improving the blood flow to the brain or both. Cognitive functions can be enhanced by improving perfusion to the brain through hyperbaric oxygen therapy [39]. Reduced cerebral blood flow was seen in $36 \%$ of persons with concussion [40]. The massage-like effect of ES in our study relaxed the cervical muscles that allowed better perfusion to the brain which in turn enhanced cognitive functions. The improvement observed in the cognitive domain may also be related to relief of neck pain or musculoskeletal functioning that indirectly improved a person's ability to focus. This could be the reason that at the end of the intervention, both groups demonstrated improvement in cognitive functions because of the accumulative effect of conventional PT.

\subsection{Cervical Rehabilitation Alleviates the Persistent Concussion-Related Symptoms}

The common treatment regimen used in both groups in the study targeted the cervical region, with a focus on cervical and periscapular strengthening and improved cervical flexibility. Manual therapy techniques we used focused on decreasing the trigger points located in the cervical and upper thoracic regions. No matter the intervention, ES included or not, we observed that the symptoms related to vestibulo-ocular functions such as vision, balance and cognition were all improved as measured by the Checklist and other secondary outcome measures, BESS, King-Devick test, SAC and some composites of the ImPACT. The 
interventions with or without ES in the current study targeting the cervical spine distinct from the brain demonstrated positive effects. This supports that the brain is unlikely to be a sole source causing clinical symptoms after concussive insults. Therefore, treating other structures such as the cervical region can alleviate persistent symptoms after concussive insults. Many other authors also suggested that the cervical spine and vestibular system, other than brain, contribute to the ongoing symptoms [12] [41]. Therefore, persons with PCS experiencing dizziness, headache etc., responded to treatments such as manual therapy [42] and vestibular rehabilitation [43]-[48]. The finding of our study, diminishing post-concussion symptoms after receiving cervical treatments seen in all participants, adds another piece of evidence that cervical spine other than brain only can be involved in the most problematic sequelae [49] after concussion. Our results also echo the evidence that conventional physical therapy targeting the cervical region has positive effects on persons with PCS who show cervicogenic symptoms [8]. We further highlight the importance of physical therapy in treating persons with PCS as a part of concussion management.

\subsection{Limitations}

The randomization procedure and small sample size of the study did not allow us to match the baselines of two groups. Compared to the control group, the ES group had relatively higher SAC scores and larger variances within the group. Furthermore, the female participants contributed to a larger portion in the ES group. Those two factors were associated with the persistent concussion symptoms reported [50] [51] [52]. These confounding factors could potentially prevent us from observing significant improvement differences between two groups after the eight-week interventions. However, our results encourage us that although the ES group had relatively severe signs and symptoms before the intervention, they recovered indifferently from the group with relatively milder signs and symptoms. Future studies should consider the baselines of two groups before the treatment. The cognitive function is often the interest of treatments after concussion. A better assessment tool that targets the cognitive functions and provides objective results is needed yet not available to detect important changes. In our study, we used the Checklist to successfully detect the recovery rate differences between two groups. But we did not detect the differences after eight-week intervention between groups. A potential non-physiological factor might be the SAC was not sensitive enough to detect the changes of recruited participants in our study. SAC has been proven to detect concussion on the sidelines [53]. However, the recruited participants in our study had relatively higher scores of SAC, the resolutions of the SAC scale could not detect the changes.

\section{Conclusions}

Individuals with PCS recruited in our study were experiencing concussion-related symptoms relief by the end of eight-week interventions in both groups. The re- 
sults support that physical therapy targeting the cervical region is beneficial for persons with persistent post concussive symptoms. Peripheral electrical stimulation on the paraspinal neck muscles could potentially advance the cognitive function recovery of persons with PCS. Future research to examine the effect of other factors such as various electrical stimulation protocols, age, gender, cognitive status and the onset of concussion is essential.

\section{Acknowledgements}

This study is supported by the Oak Foundation (OCAY-16-310). We acknowledge and thank all of participants and families who took part in the study.

\section{Conflicts of Interest and Source of Funding}

Dr. Cantu has following disclosure of conflicts of interest: Senior Advisor of NFL Head Neck \& Spine Committee, VP NOCSAE and Chair of Scientific Advisory Committee, Co-Founder of Medical Director Concussion Legacy Foundation, royalties from Houghton Mifflin Harcourt.

This study is supported by the Oak Foundation (OCAY-16-310).

The study was partially presented in the 2017 American Society of Neurorehabilitation Annual Meeting this November in Baltimore, Maryland, USA.

\section{References}

[1] Tator, C., Bray, G. and Morin, D. (2007) The CBANCH Report-The Burden of Neurological Diseases, Disorders, and Injuries in Canada. Canadian Journal of Neurological Sciences, 34, 268-269. https://doi.org/10.1017/S0317167100006673

[2] Langlois, J.A., Rutland-Brown, W. and Wald, M.M. (2006) The Epidemiology and Impact of Traumatic Brain Injury: A Brief Overview. Journal of Head Trauma Rehabilitation, 21, 375-378. https://doi.org/10.1097/00001199-200609000-00001

[3] McCrory, P., Meeuwisse, W., Aubry, M., Cantu, B., Dvorak, J., Echemendia, R.J., Engebretsen, L., Johnston, K., Kutcher, J.S., Raftery, M., Sills, A., Benson, B.W., Davis, G.A., Ellenbogen, R.G., Guskiewicz, K.M., Herring, S.A., Iverson, G., Jordan, B.D., Kissick, J., McCrea, M., McIntosh, A.S., Maddocks, D.L., Makdissi, M., Purcell, L., Putukian, M., Turner, M., Schneider, K. and Tator, C.H. (2013) Consensus Statement on Concussion in Sport-The 4th International Conference on Concussion in Sport held in Zurich, November 2012. Clinical Journal of Sport Medicine, 23, 89-117. https://doi.org/10.1097/JSM.0b013e31828b67cf

[4] Vidal, P.G., Goodman, A.M., Colin, A., Leddy, J.J. and Grady, M.F. (2012) Rehabilitation Strategies for Prolonged Recovery in Pediatric and Adolescent Concussion. Pediatric Annals, 41, 1-7. https://doi.org/10.3928/00904481-20120827-10

[5] Bazarian, J.J., Wong, T., Harris, M., Leahey, N., Mookerjee, S. and Dombovy, M. (1999) Epidemiology and Predictors of Post-Concussive Syndrome after Minor Head Injury in an Emergency Population. Brain Injury, 13, 173-189. https://doi.org/10.1080/026990599121692

[6] Iverson, G.L. (2005) Outcome from Mild Traumatic Brain Injury. Current Opinion in Psychiatry, 18, 301-317. https://doi.org/10.1097/01.yco.0000165601.29047.ae

[7] Leddy, J.J., Sandhu, H., Sodhi, V., Baker, J.G. and Willer, B. (2012) Rehabilitation of Concussion and Post-Concussion Syndrome. Sports Health, 4, 147-154. 
https://doi.org/10.1177/1941738111433673

[8] Schneider, K.J., Iverson, G.L., Emery, C.A., McCrory, P., Herring, S.A. and Meeuwisse, W.H. (2013) The Effects of Rest and Treatment Following Sport-Related Concussion: A Systematic Review of the Literature. British Journal of Sports Medicine, 47, 304-307. https://doi.org/10.1136/bjsports-2013-092190

[9] Majerske, C.W., Mihalik, J.P., Ren, D., Collins, M.W., Reddy, C.C., Lovell, M.R. and Wagner, A.K. (2008) Concussion in Sports: Postconcussive Activity Levels, Symptoms, and Neurocognitive Performance. Journal of Athletic Training, 43, 265-274. https://doi.org/10.4085/1062-6050-43.3.265

[10] McCrory, P., Johnston, K., Meeuwisse, W., Aubry, M., Cantu, R., Dvorak, J., Graf-Baumann, T., Kelly, J., Lovell, M. and Schamasch, P. (2005) Summary and Agreement Statement of the 2nd International Conference on Concussion in Sport, Prague 2004. Clinical Journal of Sport Medicine, 15, 48-55.

https://doi.org/10.1097/01.jsm.0000159931.77191.29

[11] Leddy, J.J., Kozlowski, K., Donnelly, J.P., Pendergast, D.R., Epstein, L.H. and Willer, B. (2010) A Preliminary Study of Subsymptom Threshold Exercise Training for Refractory Post-Concussion Syndrome. Clinical Journal of Sport Medicine, 20, 21-27. https://doi.org/10.1097/JSM.0b013e3181c6c22c

[12] Kennedy, E., Quinn, D., Tumilty, S. and Chapple, C.M. (2017) Clinical Characteristics and Outcomes of Treatment of the Cervical Spine in Patients with Persistent Post-Concussion Symptoms: A Retrospective Analysis. Musculoskeletal Science and Practice, 29, 91-98. https://doi.org/10.1016/j.msksp.2017.03.002

[13] Giza, C.C., Kutcher, J.S., Ashwal, S., Barth, J., Getchius, T.S., Gioia, G.A., Gronseth, G.S., Guskiewicz, K., Mandel, S., Manley, G., McKeag, D.B., Thurman, D.J. and Zafonte, R. (2013) Summary of Evidence-Based Guideline Update: Evaluation and Management of Concussion in Sports: Report of the Guideline Development Subcommittee of the American Academy of Neurology. Neurology, 80, 2250-2257. https://doi.org/10.1212/WNL.0b013e31828d57dd

[14] Herring, S.A., Cantu, R.C., Guskiewicz, K.M., Putukian, M., Kibler, W.B., Bergfeld, J.A., Boyajian-O'Neill, L.A., Franks, R.R., Indelicato, P.A. and American College of Sports, M. (2011) Concussion (Mild Traumatic Brain Injury) and the Team Physician: A Consensus Statement-2011 Update. Medicine \& Science in Sports \& Exercise, 43, 2412-2422. https://doi.org/10.1249/MSS.0b013e3182342e64

[15] Stern, R.A., Seichepine, D., Tschoe, C., Fritts, N.G., Alosco, M.L., Berkowitz, O., Burke, P., Howland, J., Olshaker, J., Cantu, R.C., Baugh, C.M. and Holsapple, J.W. (2017) Concussion Care Practices and Utilization of Evidence-Based Guidelines in the Evaluation and Management of Concussion: A Survey of New England Emergency Departments. Journal of Neurotrauma, 34, 861-868. https://doi.org/10.1089/neu.2016.4475

[16] Ellis, M.J., Leddy, J. and Willer, B. (2016) Multi-Disciplinary Management of Athletes with Post-Concussion Syndrome: An Evolving Pathophysiological Approach. Frontiers in Neurology, 7, 136. https://doi.org/10.3389/fneur.2016.00136

[17] Leddy, J.J., Baker, J.G. and Willer, B. (2016) Active Rehabilitation of Concussion and Post-Concussion Syndrome. Physical Medicine \& Rehabilitation Clinics of North America, 27, 437-454. https://doi.org/10.1016/j.pmr.2015.12.003

[18] Ellis, M.J., Leddy, J.J. and Willer, B. (2015) Physiological, Vestibulo-Ocular and Cervicogenic Post-Concussion Disorders: An Evidence-Based Classification System with Directions for Treatment. Brain Injury, 29, 238-248.

https://doi.org/10.3109/02699052.2014.965207 
[19] Jull, G., Trott, P., Potter, H., Zito, G., Niere, K., Shirley, D., Emberson, J., Marschner, I. and Richardson, C. (2002) A Randomized Controlled Trial of Exercise and Manipulative Therapy for Cervicogenic Headache. Spine, 27, 1835-1843.

[20] Reid, S.A., Callister, R., Snodgrass, S.J., Katekar, M.G. and Rivett, D.A. (2015) Manual Therapy for Cervicogenic Dizziness: Long-Term Outcomes of a Randomised Trial. Manual Therapy, 20, 148-156. https://doi.org/10.1016/j.math.2014.08.003

[21] Johnson, M.I., Claydon, L.S., Herbison, G.P., Jones, G. and Paley, C.A. (2017) Transcutaneous Electrical Nerve Stimulation (TENS) for Fibromyalgia in Adults. The Cochrane Database of Systematic Reviews, 10, CD012172.

[22] Price, C.I. and Pandyan, A.D. (2001) Electrical Stimulation for Preventing and Treating Post-Stroke Shoulder Pain: A Systematic Cochrane Review. Clinical Rehabilitation, 15, 5-19. https://doi.org/10.1191/026921501670667822

[23] Doucet, B.M., Lam, A. and Griffin, L. (2012) Neuromuscular Electrical Stimulation for Skeletal Muscle Function. The Yale Journal of Biology and Medicine, 85, 201-215.

[24] Chuang, L.L., Chen, Y.L., Chen, C.C., Li, Y.C., Wong, A.M., Hsu, A.L. and Chang, Y.J. (2017) Effect of EMG-Triggered Neuromuscular Electrical Stimulation with Bilateral Arm Training on Hemiplegic Shoulder Pain and Arm Function after Stroke: A Randomized Controlled Trial. Journal of NeuroEngineering and Rehabilitation, 14, 122. https://doi.org/10.1186/s12984-017-0332-0

[25] Jonsdottir, S., Bouma, A., Sergeant, J.A. and Scherder, E.J. (2004) Effects of Transcutaneous Electrical Nerve Stimulation (TENS) on Cognition, Behavior, and the Rest-Activity Rhythm in Children with Attention Deficit Hyperactivity Disorder, Combined Type. Neurorehabilitation and Neural Repair, 18, 212-221. https://doi.org/10.1177/1545968304270759

[26] van Dijk, K.R., Scherder, E.J., Scheltens, P. and Sergeant, J.A. (2002) Effects of Transcutaneous Electrical Nerve Stimulation (TENS) on Non-Pain Related Cognitive and Behavioural Functioning. Reviews in the Neurosciences, 13, 257-270. https://doi.org/10.1515/REVNEURO.2002.13.3.257

[27] Scherder, E.J., Van Someren, E.J., Bouma, A. and Berg, M. (2000) Effects of Transcutaneous Electrical Nerve Stimulation (TENS) on Cognition and Behaviour in Aging. Behavioural Brain Research, 111, 223-225. https://doi.org/10.1016/S0166-4328(00)00170-4

[28] Hitier, M., Besnard, S. and Smith, P.F. (2014) Vestibular Pathways Involved in Cognition. Frontiers in Integrative Neuroscience, 8, 59. https://doi.org/10.3389/fnint.2014.00059

[29] Skinner, S.B. and McVey, C. (2012) Pocket Notes for the Physical Therapist Assistant. Jones \& Bartlett Learning, Burlington.

[30] Travell, J. and Simons, D. (1992) Myofascial Pain and Dysfunction: The Trigger Point Manual. Williams \& Wikins, Philadelphia.

[31] Cantu, R.C. (2017) History of Concussion and Chronic Traumatic Encephalopathy. In: Budson, A., Mckee, A., Cantu, R.C. and Stern, R.A., Eds., Chronic Traumatic Encephalopathy, Elsevier, New York, 11.

[32] Cantu, R.C. (2003) Recurrent Athletic Head Injury: Risks and When to Retire. Clinics in Sports Medicine, 22, 593-603. https://doi.org/10.1016/S0278-5919(02)00095-9

[33] Merritt, V.C., Bradson, M.L., Meyer, J.E. and Arnett, P.A. (2017) Evaluating the Test-Retest Reliability of Symptom Indices Associated with the Impact Post-Concussion Symptom Scale (PCSS). Journal of Clinical and Experimental 
Neuropsychology, 40, 377-388.

[34] McCrory, P., Meeuwisse, W., Dvorak, J., Aubry, M., Bailes, J., Broglio, S., Cantu, R.C., Cassidy, D., Echemendia, R.J., Castellani, R.J., Davis, G.A., Ellenbogen, R., Emery, C., Engebretsen, L., Feddermann-Demont, N., Giza, C.C., Guskiewicz, K.M., Herring, S., Iverson, G.L., Johnston, K.M., Kissick, J., Kutcher, J., Leddy, J.J., Maddocks, D., Makdissi, M., Manley, G.T., McCrea, M., Meehan, W.P., Nagahiro, S., Patricios, J., Putukian, M., Schneider, K.J., Sills, A., Tator, C.H., Turner, M. and Vos, P.E. (2017) Consensus Statement on Concussion in Sport-The 5th International Conference on Concussion in Sport Held in Berlin, October 2016. British Journal of Sports Medicine, 51, 838-847.

[35] Pearce, A.J., Hoy, K., Rogers, M.A., Corp, D.T., Davies, C.B., Maller, J.J. and Fitzgerald, P.B. (2015) Acute Motor, Neurocognitive and Neurophysiological Change Following Concussion Injury in Australian Amateur Football. A Prospective Multimodal Investigation. Journal of Science and Medicine in Sport, 18, 500-506. https://doi.org/10.1016/j.jsams.2014.07.010

[36] O’Brien, A.M., Casey, J.E. and Salmon, R.M. (2017) Short-Term Test-Retest Reliability of the ImPACT in Healthy Young Athletes. Applied Neuropsychology: Child, 1-9. https://doi.org/10.1080/21622965.2017.1290529

[37] Galetta, K.M., Brandes, L.E., Maki, K., Dziemianowicz, M.S., Laudano, E., Allen, M., Lawler, K., Sennett, B., Wiebe, D., Devick, S., Messner, L.V., Galetta, S.L. and Balcer, L.J. (2011) The King-Devick Test and Sports-Related Concussion: Study of a Rapid Visual Screening Tool in a Collegiate Cohort. Journal of the Neurological Sciences, 309, 34-39. https://doi.org/10.1016/j.jns.2011.07.039

[38] Turner, M. (2013) SCAT3. British Journal of Sports Medicine, 47, 259-262.

[39] Tal, S., Hadanny, A., Berkovitz, N., Sasson, E., Ben-Jacob, E. and Efrati, S. (2015) Hyperbaric Oxygen May Induce Angiogenesis in Patients Suffering from Prolonged Post-Concussion Syndrome Due to Traumatic Brain Injury. Restorative Neurology and Neuroscience, 33, 943-951. https://doi.org/10.3233/RNN-150585

[40] Maugans, T.A., Farley, C., Altaye, M., Leach, J. and Cecil, K.M. (2012) Pediatric Sports-Related Concussion Produces Cerebral Blood Flow Alterations. Pediatrics, 129, 28-37. https://doi.org/10.1542/peds.2011-2083

[41] Morin, M., Langevin, P. and Fait, P. (2016) Cervical Spine Involvement in Mild Traumatic Brain Injury: A Review. Journal of Sports Medicine, 2016, Article ID: 1590161. https://doi.org/10.1155/2016/1590161

[42] Burns, S.L. (2015) Concussion Treatment Using Massage Techniques: a Case Study. International Journal of Therapeutic Massage \& Bodywork, 8, 12-17.

[43] Horak, F.B., Jones-Rycewicz, C., Black, F.O. and Shumway-Cook, A. (1992) Effects of Vestibular Rehabilitation on Dizziness and Imbalance. Otolaryngology-Head and Neck Surgery, 106, 175-180.

[44] Krebs, D.E., Gill-Body, K.M., Riley, P.O. and Parker, S.W. (1993) Double-Blind, Placebo-Controlled Trial of Rehabilitation for Bilateral Vestibular Hypofunction: Preliminary Report. Otolaryngology_Head and Neck Surgery, 109, 735-741. https://doi.org/10.1177/019459989310900417

[45] Shepard, N.T., Telian, S.A., Smith-Wheelock, M. and Raj, A. (1993) Vestibular and Balance Rehabilitation Therapy. Annals of Otology, Rhinology \& Laryngology, 102, 198-205. https://doi.org/10.1177/000348949310200306

[46] Alsalaheen, B.A., Mucha, A., Morris, L.O., Whitney, S.L., Furman, J.M., Camiolo-Reddy, C.E., Collins, M.W., Lovell, M.R. and Sparto, P.J. (2010) Vestibular Rehabilitation for Dizziness and Balance Disorders after Concussion. Journal of Neu- 
rologic Physical Therapy, 34, 87-93.

https://doi.org/10.1097/NPT.0b013e3181dde568

[47] Gottshall, K. (2011) Vestibular Rehabilitation after Mild Traumatic Brain Injury with Vestibular Pathology. NeuroRehabilitation, 29, 167-171.

[48] Schneider, K.J., Meeuwisse, W.H., Nettel-Aguirre, A., Barlow, K., Boyd, L., Kang, J. and Emery, C.A. (2014) Cervicovestibular Rehabilitation in Sport-Related Concussion: A Randomised Controlled Trial. British Journal of Sports Medicine, 48, 1294-1298. https://doi.org/10.1136/bjsports-2013-093267

[49] Wallace, B. and Lifshitz, J. (2016) Traumatic Brain Injury and Vestibulo-Ocular Function: Current Challenges and Future Prospects. Eye Brain, 8, 153-164. https://doi.org/10.2147/EB.S82670

[50] Makdissi, M., Davis, G., Jordan, B., Patricios, J., Purcell, L. and Putukian, M. (2013) Revisiting the Modifiers: How Should the Evaluation and Management of Acute Concussions Differ in Specific Groups? British Journal of Sports Medicine, 47, 314-320. https://doi.org/10.1136/bjsports-2013-092256

[51] Baker, J.G., Leddy, J.J., Darling, S.R., Rieger, B.P., Mashtare, T.L., Sharma, T. and Willer, B.S. (2015) Factors Associated with Problems for Adolescents Returning to the Classroom after Sport-Related Concussion. Clinical Pediatrics, 54, 961-968. https://doi.org/10.1177/0009922815588820

[52] Covassin, T. and Elbin, R.J. (2011) The Female Athlete: The Role of Gender in the Assessment and Management of Sport-Related Concussion. Clinics in Sports Medicine, 30, 125-131. https://doi.org/10.1016/j.csm.2010.08.001

[53] McCrea, M., Kelly, J.P., Randolph, C., Kluge, J., Bartolic, E., Finn, G. and Baxter, B. (1998) Standardized Assessment of Concussion (SAC): On-Site Mental Status Evaluation of the Athlete. The Journal of Head Trauma Rehabilitation, 13, 27-35. https://doi.org/10.1097/00001199-199804000-00005 